\title{
Phantom dosimetry and image quality of i-CAT FLX cone-beam computed tomography
}

\author{
John B. Ludlow, DDS, MS, FDS, RCSEd ${ }^{1, \dagger}$ and Cameron Walker, DDS, MS, $\mathrm{PhD}^{2}$ \\ ${ }^{1}$ Professor, Department of Diagnostic Sciences, University of North Carolina School of Dentistry, \\ Chapel Hill, North Carolina, USA \\ ${ }^{2}$ Adjunct Assistant Professor, Faculty of Orthodontics, University of Missouri - Kansas City, \\ School of Dentistry, Kansas City, Missouri, USA
}

\begin{abstract}
Introduction-Increasing use of cone-beam computed tomography in orthodontics has been coupled with heightened concern with the long-term risks of x-ray exposure in orthodontic populations. An industry response to this has been to offer low-exposure alternative scanning options in newer cone-beam computed tomography models.
\end{abstract}

\begin{abstract}
Methods-Effective doses resulting from various combinations of field size, and field location comparing child and adult anthropomorphic phantoms using the recently introduced i-CAT FLX cone-beam computed tomography unit were measured with Optical Stimulated Dosimetry using previously validated protocols. Scan protocols included High Resolution $\left(360^{\circ}\right.$ rotation, 600 image frames, $120 \mathrm{kVp}, 5 \mathrm{~mA}, 7.4 \mathrm{sec})$, Standard $\left(360^{\circ}, 300\right.$ frames, $\left.120 \mathrm{kVp}, 5 \mathrm{~mA}, 3.7 \mathrm{sec}\right)$, QuickScan $\left(180^{\circ}, 160\right.$ frames, $\left.120 \mathrm{kVp}, 5 \mathrm{~mA}, 2 \mathrm{sec}\right)$ and QuickScan $+\left(180^{\circ}, 160\right.$ frames, $90 \mathrm{kVp}$, $3 \mathrm{~mA}, 2 \mathrm{sec}$ ). Contrast-to-noise ratio (CNR) was calculated as a quantitative measure of image quality for the various exposure options using the QUART DVT phantom.
\end{abstract}

Results-Child phantom doses were on average 36\% greater than Adult phantom doses. QuickScan+ protocols resulted in significantly lower doses than Standard protocols for child $(\mathrm{p}=0.0167)$ and adult $(\mathrm{p}=0.0055)$ phantoms. $13 \times 16 \mathrm{~cm}$ cephalometric fields of view ranged from 11-85 $\mu \mathrm{Sv}$ in the adult phantom and 18-120 $\mu \mathrm{Sv}$ in the child for QuickScan+ and Standard protocols respectively. CNR was reduced by approximately 2/3rds comparing QuickScan+ to Standard exposure parameters.

Conclusions-QuickScan+ effective doses are comparable to conventional panoramic examinations. Significant dose reductions are accompanied by significant reductions in image quality. However, this trade-off may be acceptable for certain diagnostic tasks such as interim assessment of treatment results.

(C) 2013 American Association of Orthodontists. Published by Mosby, Inc. All rights reserved.

${ }^{\dagger}$ North Carolina Oral Health Institute, Koury Oral Health Sciences, Room 5411-K, 385 South Columbia Street, Chapel Hill, NC 27599-7455, Office: 919-537-3141, Fax: 919-966-0705, jbl@email.unc.edu.

Dr. Walker participated in background research, data evaluation, and manuscript preparation

Dr. Ludlow participated in protocol development, data gathering, statistical evaluation, and manuscript preparation

Publisher's Disclaimer: This is a PDF file of an unedited manuscript that has been accepted for publication. As a service to our customers we are providing this early version of the manuscript. The manuscript will undergo copyediting, typesetting, and review of the resulting proof before it is published in its final citable form. Please note that during the production process errors may be discovered which could affect the content, and all legal disclaimers that apply to the journal pertain. 


\section{Introduction and literature review}

The use of cone-beam computed tomography (CBCT) in orthodontics has increased dramatically over the last few years.(1) Because cancer is the principal long-term biological effect of exposure to x-rays, one of the greatest issues facing CBCT in orthodontics is justification of the increased dose of ionizing radiation administered to patients compared to standard 2D imaging techniques.

A routine medical CT head scan may have an effective dose of approximately $2 \mathrm{mSv}(2)$. While the majority of CBCT examinations have been reported to impart a much lower dose, CBCT units from different manufacturers have been shown to vary in patient dose 10 fold for an equivalent field of view (FOV), with some units roughly equivalent in dose to optimized CT scans(3). Although the risk to an individual from a single CT or CBCT examination may not itself be large, millions of exams are performed each year, making radiation exposure from dental and medical imaging an important public health issue. It has been estimated that from $1.5 \%$ to $2 \%$ of all US cancers may be attributed to computed tomography (CT) studies alone(4). This is especially important when considering the adolescent and pediatric populations that routinely receive orthodontic treatment in whom cellular growth and organ development is associated with increased radiosensitivity of tissues. In conjunction with a longer life expectancy in which cancer can develop, children may be two times to five times more sensitive to radiation carcinogenesis as mature adults(2, $5)$.

"Image quality" in CBCT is observer dependent, subjective and is used to describe how well desired information can be extracted from an image. Because it is subjective by nature, the measurement and comparison of image quality across CBCT units in diagnostic situations remains a complex problem. Two of the elements of subjective image quality that correlate with objective quality measures include contrast and spatial resolution (6). Image contrast can be objectively measured via the Contrast to Noise Ratio (CNR) while spatial resolution can be measured by computing a Modulation Transfer Function (MTF). The quality of CBCT scans is also an important consideration for users in orthodontics because a selection of image quality for a CBCT scan becomes a decision on dose and vice versa. Image quality technical factor adjustments that select between "high" and "low" image quality in many CBCT units can cause as much as 7 fold differences in dose(3).

The ongoing challenge in the optimization of CBCT is to reduce dose without drastically decreasing imaging quality and diagnostic information. A potential means of reducing patient risk from CBCT examinations is to limit the area of exposure by utilizing variable fields of view that are sized for the location of the anatomy of interest. However, voxel size is linked to FOV in many CBCT units and smaller voxel sizes associated with smaller FOVs may actually increase dose due to increases in exposure that are needed to maintain adequate CNR. Another approach is to reduce exposure for diagnostic tasks that theoretically require lower contrast to noise ratios or lower signal modulation transfer functions. An example of this type of task might be checking angulation of roots. The combination of careful selection of exposure parameters and field of view may result in an optimal use of dose for specific diagnostic tasks in orthodontic practice.

The purpose of this study was to evaluate doses resulting from various combinations of field size, location, and exposure parameters using child and adult phantoms with the i-CAT FLX unit. A second aim was to measure contrast to noise ratio (CNR) and modulation transfer function (MTF) as quantitative measures of image quality for the various exposure options offered by the i-CAT FLX. A tertiary aim was to compare phantom sizes and types as well 
as Thermoluminescent dosimetry (TLD) and Optically stimulated luminescent dosimetry (OSL).

\section{Materials and Methods}

Optically stimulated luminescent dosimeters (Nanodot, Landauer, Inc., Glenwood, IL) are plastic disks infused with aluminum oxide doped with carbon $\left(\mathrm{Al}_{2} \mathrm{O}_{3}: \mathrm{C}\right)$. The trace amounts of Carbon in the $\mathrm{Al}_{2} \mathrm{O}_{3}$ crystal lattice create imperfections that act as traps (F centers) for electrons or holes. After exposure to ionizing radiation, free electrons and holes are generated and trapped at the $\mathrm{F}$ centers in proportion to the amount of energy in the exposure. Energy captured by the F centers is reemitted as light when electrons or holes recombine. This occurs when the crystal is optically stimulated with a controlled exposure of $540 \mathrm{~nm}$ light from a light emitting diode. The energy released from $\mathrm{F}$ centers can be distinguished from the stimulating light because it is emitted in the form of $420 \mathrm{~nm}$ photons. The intensity of the emitted luminescence depends on the dose absorbed by the OSLD and the intensity of the stimulating light. This intensity is proportional to the stored dose and is recorded by a photomultiplier tube that incorporates a filter that screens out photons from the stimulating light source. Each dosimeter is encased in a light-tight plastic holder measuring approximately $1 \mathrm{~mm} \times 10 \mathrm{~mm} \times 10 \mathrm{~mm}$. This case prevents loss of energy through stimulation by ambient light. Dosimeters used in this study were read with a portable reader (MicroStar, Landauer, Inc., Glenwood, IL). The reader was calibrated before use. Following calibration, photon counts from dosimeters may be recorded with an accuracy of $\sim+/-2 \%$. Photon counts are converted to dose using an energy specific conversion factor. Doses reported by the reader were adjusted for energy response using a $3^{\text {rd }}$ order polynomial calibration curve derived from side-by-side comparison of recorded doses from an ion chamber and OSL dosimeters over a range of $80-120 \mathrm{kVp}$ using an adjustable $\mathrm{kVp}$ source. For this study, the OSL sensitivity at $90 \mathrm{kVp}$ was estimated at .94 (mean $\mathrm{kV}=60$ ). OSL sensitivity at $120 \mathrm{kVp}$ was estimated at $0.78($ mean $\mathrm{kV}=80)$.

A software and hardware upgraded model of the i-CAT Next Generation dental CBCT unit (Imaging Sciences, Hatfield PA) was investigated in this study. The unit was updated to meet specifications that are named "i-CAT FLX". Volume scans for this unit range from 8 $\mathrm{cm} \times 8 \mathrm{~cm}$ to $23 \mathrm{~cm} \times 17 \mathrm{~cm}$. The unit operates at $90 \mathrm{kVp}$ or $120 \mathrm{kVp}$ and 3 or $5 \mathrm{~mA}$ with a pulsed exposure time from 2.0 to 7.4 seconds. The unit rotates through $360^{\circ}$ over 8.6 or 26 seconds. A $180^{\circ}$ rotation is also available with a rotation time of 4.8 seconds. Scan parameters used for child and adult phantoms are seen in Table 1.

Adult dosimetry was acquired using a tissue equivalent phantom simulating the anatomy of an average adult male (Atom Max Model 711 HN, CIRS Inc., Norfolk, VA). The phantom includes detailed 3D anthropomorphic anatomy including brain, bone, larynx, trachea, sinus, nasal cavities and teeth. The bones contain both cortical and trabecular separation. The phantom was modified by machining slots to accept Nanodot dosimeters at sites corresponding to internal tissues of interest. A skin surface dosimeter in the back of the neck is positioned at the vertical center of the designated slice level and taped in position. Lens of eye dosimeters are centered over and inset in the anatomic location for the lens and taped in position. Internal dosimeters are positioned vertically with the upper edge of the dosimeter slot, flush with the surface of the selected slice level and held in position by friction of the dosimeter case and the phantom material at the sampled anatomic location. Adult dosimeter anatomic locations and phantom levels are seen in (Figure 1). During scanning, the phantom was oriented with its section planes approximately parallel to the scan rotation plane (horizon). A phantom position simulating positioning of a patient on the chin rest was used. With the exception of the $13 \times 16 \mathrm{~cm}$ cephalometric and $6 \times 16 \mathrm{~cm}$ maxillary FOVs, centered FOVs were positioned to capture approximately $5 \mathrm{~mm}$ of soft tissue below the 
lower cortical border of the chin. Anterior-posterior position of the phantom was established to capture approximately $5 \mathrm{~mm}$ of soft tissue anterior to the facial surface of the maxillary incisor crown. For $6 \times 16 \mathrm{~cm}$ maxillary views, the lower border of the FOV was positioned approximately $5 \mathrm{~mm}$ below the maxillary central incisor edge. For $13 \times 16$ cephalometric views, the tip of the nose and the lower soft tissue border of the chin were included in the field of view (Figure 2).

Child dosimetry was acquired using a tissue equivalent phantom simulating the anatomy of a ten-year old child (Atom Model 706 HN, CIRS Inc., Norfolk, VA). Tissues simulated in the ATOM phantom are average soft tissue, average bone tissue, spinal cord, spinal disks, brain and sinus. Simulated bone tissue matches age-related density. Dosimeter anatomic locations and child phantom levels are seen in (Figure 3). With the exception of the $11 \times 16 \mathrm{~cm}, 13 \times$ $16 \mathrm{~cm}$ and $6 \times 16 \mathrm{~cm}$ maxillary FOVs, centered FOVs were positioned to capture approximately $5 \mathrm{~mm}$ of soft tissue below the lower cortical border of the chin. Anteriorposterior position of the phantom was established to capture approximately $5 \mathrm{~mm}$ of soft tissue anterior to the facial surface of the maxillary incisor crown. For $6 \times 16 \mathrm{~cm}$ maxillary views, the lower border of the FOV was positioned approximately $5 \mathrm{~mm}$ below the maxillary central incisor edge. For $11 \times 16$ and $13 \times 16$ cephalometric views, the tip of the nose and the lower soft tissue border of the chin were included in the field of view (Figure $4)$.

Two to twelve exposures were utilized for each dosimeter run to provide a more reliable measure of radiation in the dosimeters. Smaller FOVs require more exposure repetition because more dosimeters are outside of the field of direct exposure and absorb only small quantities of scatter radiation. For every scan, a scout view was also acquired. Doses recorded by the OSLD reader were divided by the number of scans to determine the 'exposure per examination' for each dosimeter.

Doses from OSLDs at different positions within a tissue or organ were averaged to express the average tissue-absorbed dose in micrograys $(\mu \mathrm{Gy})$. The products of these values and the percentage of a tissue or organ irradiated in a radiographic examination (Table 2) were used to calculate the equivalent dose $\left(H_{\mathrm{T}}\right)$ in micro-Sieverts $(\mu \mathrm{Sv})(7)$.

For bone, the equivalent dose to the whole-body bone surface was calculated using the summation of the individual equivalent doses to the calvarium, the mandible, and the cervical spine. The determination of these equivalent doses is based on the distribution of bone throughout the body: the mandible contains $1.3 \%$, the calvaria, $11.8 \%$, and the cervical spine, $3.4 \%$ (8). Distribution of adult bone marrow is calculated using an average of data from Christy for 25 and 40 year olds(9). The mandible contains $0.8 \%$, the calvaria, $7.7 \%$, and the cervical spine, $3.8 \%$ of the adult marrow distribution. The 10 year-old child marrow distribution is calculated as $1.1 \%$ for the mandible, $11.6 \%$ for the cranium, and $2.7 \%$ for the cervical spine for a total of $15.4 \%$ of the total body marrow.

Following the technique of Underhill and co-authors, three locations within the calvarium were averaged to determine calvarial dose(8). For bone, a correction factor based on experimentally determined mass energy attenuation coefficients for bone and muscle irradiated with mono-energetic photons was applied. An effective beam energy estimated to be $2 / 3$ rds of the peak beam energy of the x-ray unit was used to determine bone/muscle attenuation ratios. A linear fit $\left(\mathrm{R}^{2}=0.996\right)$ of ratios from 40 to $80 \mathrm{kV}$ from published data (10) produced the following equation: bone/muscle attenuation ratio $=-0.0618 \times \mathrm{kV}$ peak $\times$ $2 / 3+6.9406$. Values calculated from this equation provided a bone/muscle attenuation ratio of 3.21 at $60 \mathrm{kV}$ (90 kV peak) and 1.97 at $80 \mathrm{kV}(120 \mathrm{kV}$ peak). 
The proportion of skin surface area in the head and neck region directly exposed during maxillofacial CBCT imaging is estimated as 5\% of the total body to calculate radiation weighted dose to the skin following the procedure Ludlow and co-authors(11). Similarly, muscle and lymphatic nodes exposures are estimated to represent $5 \%$ of the total body complement for these tissues. The proportion of the esophageal tract that is exposed is set at $10 \%$. Other tissues of interest were calculated at $100 \%$.

Effective dose $(E)$ is a calculation that permits comparison of the detriment of different exposures to ionizing radiation to an equivalent detriment produced by a full body dose of radiation. $E$, expressed in $\mu \mathrm{Sv}$, is calculated using the equation: $E=\Sigma w_{\mathrm{T}} \times H_{\mathrm{T}}$, where $E$ is the summation of the products of the tissue weighting factor $\left(w_{\mathrm{T}}\right)$, which represents the relative contribution of that organ or tissue to the overall risk, and the radiation weighted dose $H_{\mathrm{T}}(7)$. The whole-body risk is determined by the summation of the radiation weighted doses to all tissues or organs exposed. ICRP 2007 weighting factors found in table 2 were used to calculate effective dose(7).

Tissue weighting factors used in the 2007 ICRP calculation of effective dose include 14 independently weighted tissues and a group of 14 remainder tissues(8). Because the uterus/ cervix is present only in females, and prostate only in males, the number used in the weighted averaging of remainder tissues is 13 .

In previous studies $(3,11)$, a RANDO phantom (radiation analog dosimetry system, Nuclear Associates, Hicksville, NY) and Thermoluminescent dosimeters (TLD) have been used for dosimetry. Because each RANDO is formed around an actual human skull, the attenuation characteristics for each RANDO varies from every other RANDO. An ATOM phantom was selected as a more reproducible model for comparative dosimetry. Effective doses were evaluated for standard and extended field cephalometric data runs and previously reported RANDO TLD data runs as well as unreported OSL runs. These were compared with the Adult ATOM phantom results of this study.

ANOVA of effective dose results was used to assess data for significant differences due to phantom type (Adult/Child), region of interest (dental/mandible/both arches/arches + TMJ/ standard ceph), and scan protocol (QuickScan+/QuickScan/Standard/High Resolution). Where significant differences were found, Tukeys HSD test was used to determine which factors were significantly different from other factors. An alpha value of 0.05 was chosen for all tests.

Image quality indicators associated with FOV, scanning angle, $\mathrm{kVp}$, and voxel size were acquired using a QUART DVT_AP phantom and QUART DVT_TEC software (QUART $\mathrm{GmbH}$, Zorneding, Germany) (figure 5). The phantom consists of $16 \mathrm{~cm}$ diameter cylindrical slabs of Plexiglas with polyvinyl chloride and air elements configured to permit measurements of Poly-methyl-methacrylate (PMMA) voxel, PMMA Noise, Homogeneity, Contrast, Contrast to Noise Ratio (CNR), Modulation Transfer Function (MTF) 10\%, MTF 50\%, and Nyquist Frequency. Measurements are calculated in a user guided, semi-automatic manner from 2 DICOM slices selected from the volume. Each volume was measured 3 times and averages and standard deviations of each measurement parameter were calculated.

\section{Results}

Volumes produced by Atom and RANDO adult phantoms for $13 \mathrm{~cm} \times 16 \mathrm{~cm}$ standard cephalometric and $17 \mathrm{~cm} \times 23 \mathrm{~cm}$ extended fields of view are seen in figure 6 . An unbiased estimator of difference between pairs $((\mathrm{A}-\mathrm{B}) /(\mathrm{A}+\mathrm{B}) / 2)$ demonstrated that OSL dosimeter readings were $1.0 \%$ less than TLD readings for Standard Cephalometric fields and $2.5 \%$ less 
for extended FOV RANDO imaging. The adult ATOM phantom effective doses were $0.2 \%$ less than RANDO doses for the Standard Cephalometric field and $0.8 \%$ less for the extended FOV.

ANOVA of combined adult and child phantom effective dose data demonstrated significant differences due to phantom ( $\mathrm{p}=0.0026)$, region of interest ( $\mathrm{p}<.0001)$, and exposure protocol ( $\mathrm{p}<.0001)$. Considering QuickScan+, QuickScan, and Standard protocols, Child phantom doses were on average $36 \%$ greater than Adult phantom doses. Table 3 highlights effective dose results for the Adult phantom. The Tukey HSD test demonstrates that the QuickScan+ protocols resulted in significantly lower doses than Standard or High Resolution protocols, but was not statistically different from QuickScan protocols. The QuickScan protocol also resulted in lower doses than High Resolution protocols but was not statistically different from Standard protocols. $13 \times 16 \mathrm{~cm}$ Cephalometric imaging resulted in statistically higher doses than all other fields of view. Similarly $6 \times 16 \mathrm{~cm}$ maxillary imaging resulted in significantly lower doses than all other fields. Results for the $17 \times 23 \mathrm{~cm}$ extended field of view (EFOV) are not included in table 3 because only standard and enhanced modes are available for this field. The effective dose for the Standard EFOV was $69 \mu \mathrm{Sv}$ while the Enhanced EFOV was $136 \mu \mathrm{Sv}$.

Table 4 highlights effective dose results for the Child phantom. The Tukey HSD test demonstrates that the each scan protocol was significantly different from the other protocols with increasing dose occurring in order of QuickScan+, QuickScan, and Standard protocols. Maxillary FOVs produced statistically lower doses than arch + TMJ and $13 \mathrm{cmx} 16 \mathrm{~cm}$ cephalometric views. Figure 7 is a graphical representation of the data in table 3. Figure 8 is a graphical representation of the data in table 4 .

Tables 5 and 6 provide equivalent doses to tissues and organs used in the calculation of effective dose. Absorbed doses in thyroid and brain are significantly greater in the child phantom than the adult phantom $(\mathrm{p}<0.0001)$.

Table 7 contains average parameter values and standard deviations from analysis of the QUART phantom images.

Increasing FOV diameter or increase in voxel size from .3 to .4 resulted in a $10 \%$ to $20 \%$ reduction in MTF. MTF 50\% demonstrated a similar pattern of little response to mAs but provided 17\% reduction in MTF with either increased FOV diameter from $8 \mathrm{~cm}$ to $16 \mathrm{~cm}$ or increase in voxel size from 3 to .4. As expected, smaller voxel sizes resulted in higher MTF values or better resolution.

\section{Discussion}

The majority of prior studies on CBCT dosimetry have used adult RANDO anthropomorphic phantoms $(3,12-14)$. However, it is understood that variations in mass, organ volume and organ position across the broad range of ages in the orthodontic patient population make it impossible to accurately estimate risk using a single type of dosimetry phantom (15). In this study we utilized both adult and 10 year old pediatric ATOM phantoms, allowing us to effectively bracket risk and thereby provide estimates that are applicable across the majority of the orthodontic patient population.

Another novel component of our study was the type of dosimeters that were used. Optically stimulated luminescent type dosimeters can be read within minutes of exposure, allow for multiple nondestructive reads, and can be erased and reused. This is significant considering this study would have required more than 1000 separate dosimeters had TLDs been used, some of which would have likely failed during the destructive read process. Hence, testing 
the many fields of view and exposure parameters possible in the i-CAT FLX would have been much less feasible without the use of OSL dosimeters. It was important to validate the results obtained with the ATOM phantoms and the OSL dosimeters by comparing them to the more common RANDO phantom and TLD data. The comparison of the different dosimeters and phantoms demonstrated differences of less than $2 \%$ in calculations of effective dose between TLD, and OSL based and in RANDO vs. ATOM phantoms. These results suggest that our current ATOM adult phantom results can be fairly compared with previous TLD results from a RANDO phantom.

There is no shortage of controversy surrounding CBCT in orthodontics. Some authors have expressed concern over the trend to use high dose, high resolution CBCT scans on young orthodontic patients as a substitute for stone study models or for the automated manufacture of custom appliances (16). Relevant to this issue, the results of our study demonstrate that effective doses were an average of $36 \%$ greater in the child phantom than in the adult. Not only is the effective dose one third higher, but due to the increased radiosensitivity of tissues, the risk is an additional $2-5 \times$ higher to a pediatric patient (5). This is important information to consider when making decisions about what type of diagnostic imaging might be best for patients. It is also important to consider the cause of differences in effective dose between the adult and child phantoms. An examination of the equivalent doses to each organ revealed that the increase in effective dose observed in the child is mostly due to the simulated anatomical position of the thyroid (Figure 9). The values calculated for thyroid dose are based on readings from two dosimeters positioned at level 10 of the Adult ATOM phantom. This is where the greatest bulk of the lobes and isthmus of the gland are located. This position is also analogous to the position of dosimeters used in the RANDO phantom, with the exception that both dosimeters are deep in the ATOM phantom while one dosimeter was superficial in the RANDO phantom. In contrast, thyroid dose calculation in the child phantom is based on two dosimeters in level 9 averaged with a single dosimeter in level 8. The rationale for this difference in dose measurement is based on the proximity of the thyroid gland to the lower border of the mandible, which is closer in children than adults (Figure 9). This proximity means that direct exposure of the thyroid is more likely in children than adults when the base of the FOV is situated just below the chin. Intensity of scatter radiation from jaw structures to the thyroid will also increase with the reduced distance of these structures in a child. Because the thyroid has a tissue weight of . 04, this organ provides a significant contribution to the calculation of effective dose for head and neck exposures. With patients, direct thyroid exposure may be reduced by rotating the chin upward and positioning the lower border of the mandible parallel with the rotational plane of the beam (parallel to the floor); however, this strategy is not possible with the ridged phantoms utilized in this research. In addition to the chin-cup, this strategy also causes difficulties for those wishing to do cephalometric analysis of soft tissue profile, especially analysis of chin/neck/throat form.

After the consideration of patient positioning and proper field of view selection, our data demonstrates that optimization of exposure parameters and filtration can greatly reduce patient dose. Here we have shown that the QuickScan+ protocol provided a substantial $87 \%$ reduction in dose compared with Standard exposure protocols in both Child and Adult phantoms. Thus, when QuickScan+ protocols can be utilized, they will provide a clinically meaningful reduction in dose. The largest Quick Scan+ dose recorded in this study (18 $\mu \mathrm{Sv})$ was for the $13 \times 16 \mathrm{~cm}$ child cephalometric scan. This dose is little more than 2 days of US per capita background radiation. It is also two orders of magnitude less than a typical medical CT head scan. The full field of view QuickScan+ protocols are also less than the combined dose of representative modern digital 2-dimensional panoramic and cephalomatric radiographs (14-24 $\mu \mathrm{S}$ and $4 \mathrm{uS}$ respectively) $(13,17)$. It is interesting to note that our 
testing of the 2D panoramic capabilities known as the iPAN demonstrated a dose of $24 \mathrm{uSv}$ for both the adult and the child phantom (i-Cat Nextgen, unpublished).

Also noteworthy for discussion, the i-CAT FLX retains its Suresmile certification. In 2012 Grunheild et al conducted dosimetry of the Suresmile scan protocol using an i-CAT Nextgen (17). The Suresmile scan protocol requires the high resolution $0.2 \mathrm{~mm}$ voxel scan. Similar to Grunheild we found that a Suresmile scan of both arches $(16 \times 8$ FOV $)$ in an adult imparts an effective dose of $148 \mu \mathrm{Sv}$. We did not conduct high resolution imaging of the pediatric phantom, however we found that pediatric phantom doses were on average $36 \%$ greater than Adult phantom doses. Hence the estimated Suresmile dose for the average orthodontic patient likely falls between $148 \mu \mathrm{Sv}$ and $198 \mu \mathrm{Sv}$.

In the quest to lower the dose of ionizing radiation administered to patients, dramatic reductions in dose are meaningless if image quality degrades to the point of being nondiagnostic. As optimization and dose reduction become more of a focus for CBCT manufactures, the effects on image quality will need close attention. Published evidence establishing the usability of low dose/low quality scans for diagnostic purposes in dentistry or in orthodontics is limited. However one potential application specific to orthodontics would be a midtreatment scan to evaluate root angulations. Additional studies are needed to confirm that other important information present in 2D imaging or higher dose scans such as gross advances in periodontal conditions, changes in root length and changes in morphology that indicate patterns of resorption are not lost in these low dose scans.

Germany is the first country to develop national standards for image quality testing of dental CBCT devices (DIN 6868-161:2013-01). The QUART DVT phantom is the first commercially available phantom which complies with those standards. In this study we evaluated the effect of the new Quickscan+ protocols on the objective components of image quality CNR and MTF using the QUART DVT phantom. Our data demonstrated that when voxel size and FOV are held constant, an increase in CNR is seen with increasing energy and mAs (QuickScan+ < QuickScan < Standard). Changes in CNR have been shown to generally correlate with observer impressions of an image (18). As CNR increases the general impression of how an image appears improves. Changes in Voxel size and FOV also influences CNR. As expected, our data demonstrated that increasing the diameter of the FOV resulted in a modest reduction in CNR, while increasing the size of the voxel from .3 to $.4 \mathrm{~mm}$ resulted in an increase in CNR. Interestingly, with High Resolution scans increasing voxel size from .125 to .25 revealed a slight trend of increased CNR. This is not dramatic and may not be clinically significant. It is important to note that is that the reduction of energy and mAs from the QuickScan to the QuickScan+ protocols reduced the effective dose to patients by a factor of 4 , but only reduced CNR by a factor of 2 . Hence the reduction of energy and mAs in the i-CAT FLX was an effective way to reduce patient dose in exchange for a modest reduction in the image quality as measured by CNR. In comparison, the objective measure of resolution, MTF was not as sensitive to the effects of $\mathrm{mAs}$ but was more sensitive to increases in FOV diameter and voxel size. Although CNR and MTF can be correlated to subjective image quality(6), additional research to evaluate the influence of CNR and MTF on diagnostic efficacy is needed.

\section{Conclusions}

The results of this study reflect a large range of imaging options that can be tailored to specific regions of interest. A variety of exposure options are also available to adjust exposure levels to accommodate a range of diagnostic tasks. Use of QuickScan and QuickScan+ imaging protocols and smaller fields of view result in significant patient dose reductions over alternate larger fields or Standard or High Resolution protocols. 
Practitioners may be guided by selection criteria in deciding which orthodontic patients are most likely to benefit from a radiographic examination and which examination is most likely to provide needed information. Such guidelines consider the balance of benefit and potential harm from diagnostic imaging. A working group of orthodontists and oral and maxillofacial radiologists has developed initial guidelines that have been adopted in a position paper by the American Academy of Oral and Maxillofacial Radiology. ${ }^{19}$ Determination of which exposure protocol is appropriate for a specific diagnostic task awaits further research. Contrast to noise ratio data in conjunction with modulation transfer function indications of resolution limits may serve as a useful guide in indicating the utility of different scanning parameters for specific diagnostic tasks.

\section{Acknowledgments}

This research was supported in part by the National Institute of Dental and Craniofacial Research of the National Institutes of Health under award number R21DE022160. The content is solely the responsibility of the authors and does not necessarily represent the official views of the National Institutes of Health.

Travel support and an honorarium were provided to Dr. Ludlow by Imaging Sciences.

\section{References}

1. Kapila S, Conley RS, Harrell WE Jr. The current status of cone beam computed tomography in orthodontics. Dentomaxillofac Radiol. 2011 Jan.40:24-34. [PubMed: 21159912]

2. Smith-Bindman R, Lipson J, Marcus R, Kim KP, Mahesh M, Gould R, et al. Radiation dose associated with common computed tomography examinations and the associated lifetime attributable risk of cancer. Arch Intern Med. 2009 Dec 14.169:2078-86. [PubMed: 20008690]

3. Ludlow JB, Ivanovic M. Comparative dosimetry of dental CBCT devices and 64-slice CT for oral and maxillofacial radiology. Oral Surg Oral Med Oral Pathol Oral Radiol Endod. 2008 Jul.106:10614. [PubMed: 18504152]

4. Brenner DJ, Hall EJ. Computed tomography--an increasing source of radiation exposure. N Engl J Med. 2007 Nov 29.357:2277-84. [PubMed: 18046031]

5. Brenner D, Elliston C, Hall E, Berdon W. Estimated risks of radiation-induced fatal cancer from pediatric CT. AJR Am J Roentgenol. 2001 Feb.176:289-96. [PubMed: 11159059]

6. Watanabe H, Honda E, Tetsumura A, Kurabayashi T. A comparative study for spatial resolution and subjective image characteristics of a multi-slice CT and a cone-beam CT for dental use. Eur J Radiol. 2011 Mar.77:397-402. [PubMed: 19819091]

7. Valentin J. The 2007 Recommendations of the International Commission on Radiological Protection. Publication 93. Ann ICRP. 2007; 37:1-332.

8. Underhill TE, Chilvarquer I, Kimura K, Langlais RP, McDavid WD, Preece JW, et al. Radiobiologic risk estimation from dental radiology. Part I. Absorbed doses to critical organs. Oral Surg Oral Med Oral Pathol. 1988 Jul.66:111-20. [PubMed: 3165508]

9. Cristy M. Active bone marrow distribution as a function of age in humans. Phys Med Biol. 1981 May.26:389-400. [PubMed: 7243876]

10. NBS handbook no. 85. Anonymous US Government Printing Office; 1963. Physical aspects of irradiation.

11. Ludlow JB, Davies-Ludlow LE, Brooks SL. Dosimetry of two extraoral direct digital imaging devices: NewTom cone beam CT and Orthophos Plus DS panoramic unit. Dentomaxillofac Radiol. 2003 Jul.32:229-34. [PubMed: 13679353]

12. Ludlow JB, Davies-Ludlow LE, Brooks SL, Howerton WB. Dosimetry of 3 CBCT devices for oral and maxillofacial radiology: CB Mercuray, NewTom 3G and i-CAT. Dentomaxillofac Radiol. 2006 Jul.35:219-26. [PubMed: 16798915]

13. Ludlow JB, Davies-Ludlow LE, White SC. Patient risk related to common dental radiographic examinations: the impact of 2007 International Commission on Radiological Protection recommendations regarding dose calculation. J Am Dent Assoc. 2008 Sep.139:1237-43. [PubMed: 18762634] 
14. Pauwels R, Beinsberger J, Stamatakis H, Tsiklakis K, Walker A, Bosmans H, et al. Comparison of spatial and contrast resolution for cone-beam computed tomography scanners. Oral Surg Oral Med Oral Pathol Oral Radiol. 2012 Jul.114:127-35. [PubMed: 22727102]

15. Cassola VF, Milian FM, Kramer R, de Oliveira Lira CA, Khoury HJ. Standing adult human phantoms based on 10th, 50th and 90th mass and height percentiles of male and female Caucasian populations. Phys Med Biol. 2011 Jul 7.56:3749-72. [PubMed: 21628776]

16. Bogdanich, WMJ. The New York Times. 2010 Nov 23. Radiation worries for children in dentists' chairs. (NY ed)Sect. A:1

17. Grunheid T, Kolbeck Schieck JR, Pliska BT, Ahmad M, Larson BE. Dosimetry of a cone-beam computed tomography machine compared with a digital x-ray machine in orthodontic imaging. Am J Orthod Dentofacial Orthop. 2012 Apr.141:436-43. [PubMed: 22464525]

18. Lin, Y.; Wang, X.; Sehnert, WJ.; Foos, DH.; Barski, L.; Samei, E. Quantification of radiographic image quality based on patient anatomical contrast-to-noise ratio: a preliminary study with chest images. Medical Imaging 2010: Image Perception, Observer Performance, and Technology Assessment; Proc. SPIE; March 03, 2010; p. 76271F

19. American Academy of Oral and Maxillofacial Radiology. Clinical Recommendations Regarding Use of Cone Beam Computed Tomography (CBCT) in Orthodontics. Position Statement by the American Academy of Oral and Maxillofacial Radiology. Oral Surg Oral Med Oral Pathol Oral Radiol. 2013 Aug.116:238-257. [PubMed: 23849378] 


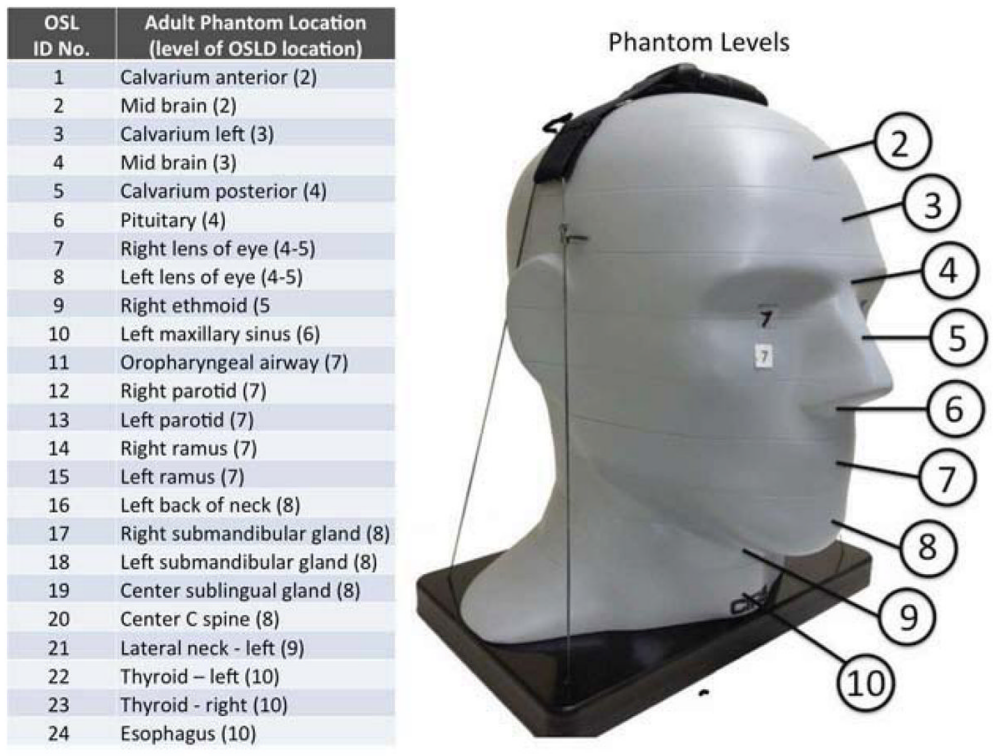

Figure 1.

Locations of optically stimulated luminescent dosimeters (OSLD) in adult Atom Max Model 711 phantom 

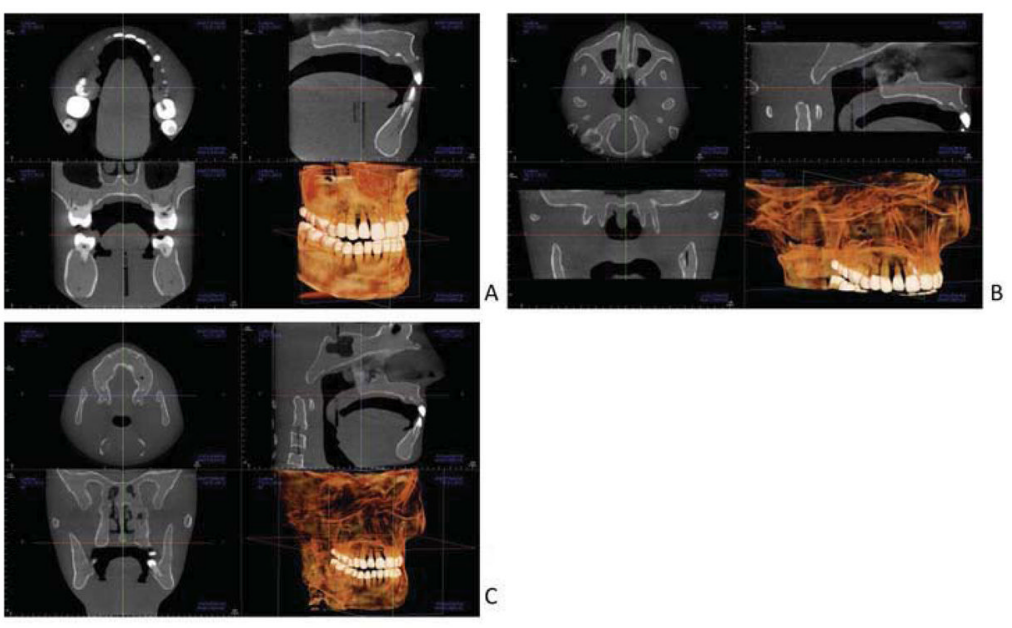

Figure 2.

Adult phantom demonstrating positioning principles for phantom scanning: A) lower border of volume is $5 \mathrm{~mm}$ below bony chin; anterior border of volume is $5 \mathrm{~mm}$ anterior to central incisors. This positioning was used on dental $(8 \times 8 \mathrm{~cm}$ High resolution scan seen here), mandible, both arches, and arches + TMJ scans. B) lower border of volume is $5 \mathrm{~mm}$ below central incisal edge; anterior border of volume is $5 \mathrm{~mm}$ anterior to central incisors. This positioning was used on maxilla volumes $(6 \times 16 \mathrm{~cm}$ High resolution scan seen here). C) tip of the nose and lower soft tissue border of the chin are included in the field of view for standard cephalometric volumes $(13 \times 16 \mathrm{~cm}$ High resolution scan seen here $)$ and extended field of view (EFOV) volumes. 
OSL Child Phantom Location

\begin{tabular}{|c|c|}
\hline ID No. & (level of OSLD location) \\
\hline 1 & Calvarium anterior (2) \\
\hline 2 & Calvarium left (2) \\
\hline 3 & Calvarium posterior (2) \\
\hline 4 & Mid brain (2) \\
\hline 5 & Mid brain (3) \\
\hline 6 & Pituitary (4) \\
\hline 7 & Right orbit (4) \\
\hline 8 & Right lens of eye (4-5) \\
\hline 9 & Left lens of eye (4-5) \\
\hline 10 & Right maxillary sinus (5) \\
\hline 11 & Left nasal airway (5) \\
\hline 12 & Right parotid (6) \\
\hline 13 & Left parotid (6) \\
\hline 14 & Left back of neck ( 6 ) \\
\hline 15 & Right ramus (7) \\
\hline 16 & Left ramus (7) \\
\hline 17 & Right submandibular gland (7) \\
\hline 18 & Left submandibular gland (7) \\
\hline 19 & Center sublingual gland (7) \\
\hline 20 & Center C spine (8) \\
\hline 21 & Thyroid superior-left ( 8 ) \\
\hline 22 & Thyroid - left (9) \\
\hline 23 & Thyroid - right (9) \\
\hline 24 & Esophagus (9) \\
\hline
\end{tabular}

1 Calvarium anterior (2)

Cvarium left (2)

Right maxillary sinus (5)

Left nasal airway (5)

ight parotid (6)

Right submandibular gland (7)

Left submandibular gland (7)

Center sublingual gland (7)

Thyroid superior-left (8)

hyroid - right $(9)$

Esophagus (9)

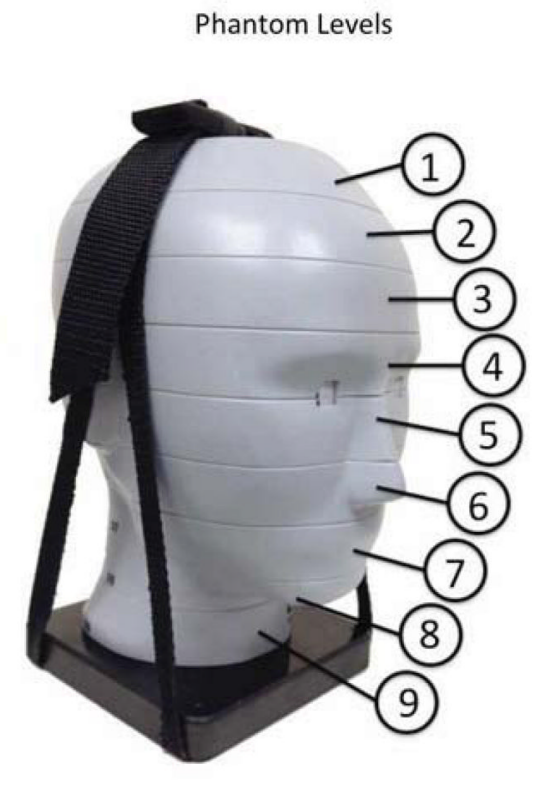

Figure 3.

CIRS 10 year-old child phantom dosimeter locations 

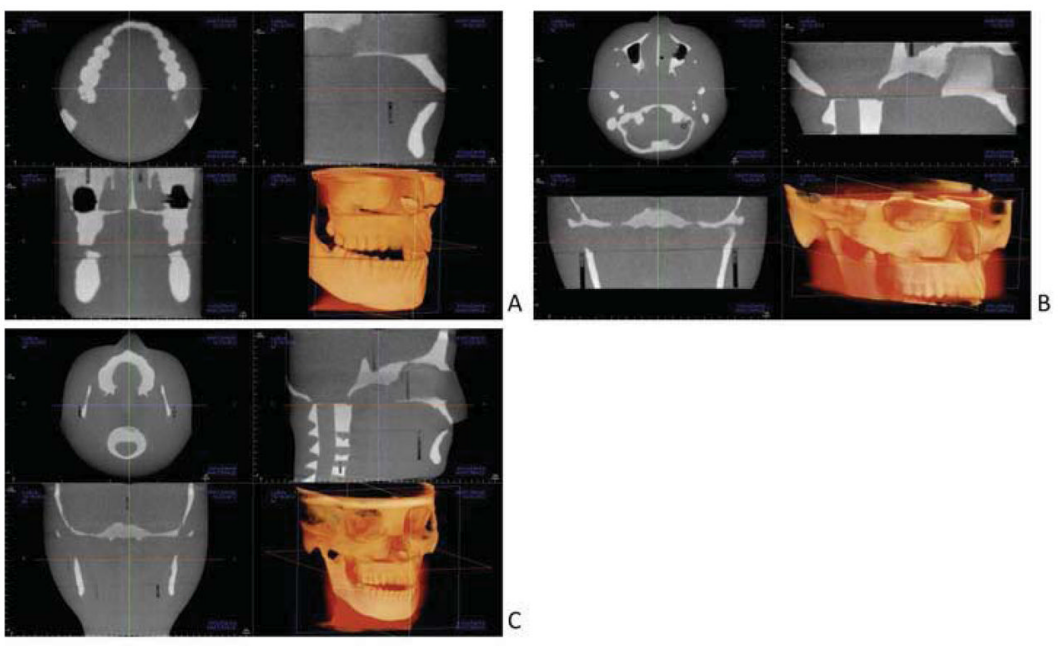

Figure 4.

Child phantom demonstrating positioning principles for phantom scanning: A) lower border of volume is $5 \mathrm{~mm}$ below bony chin; anterior border of volume is $5 \mathrm{~mm}$ anterior to central incisors. This positioning was used on dental ( $8 \times 8 \mathrm{~cm}$ High resolution scan seen here), mandible, and both arches. B) lower border of volume is $5 \mathrm{~mm}$ below central incisal edge; anterior border of volume is $5 \mathrm{~mm}$ anterior to central incisors. This positioning was used on maxilla volumes $(6 \times 16 \mathrm{~cm}$ High resolution scan seen here). C) tip of the nose and lower soft tissue border of the chin are included in the field of view for standard cephalometric volumes $(13 \times 16 \mathrm{~cm}$ High resolution scan seen here $)$ and arches + TMJ scans. 

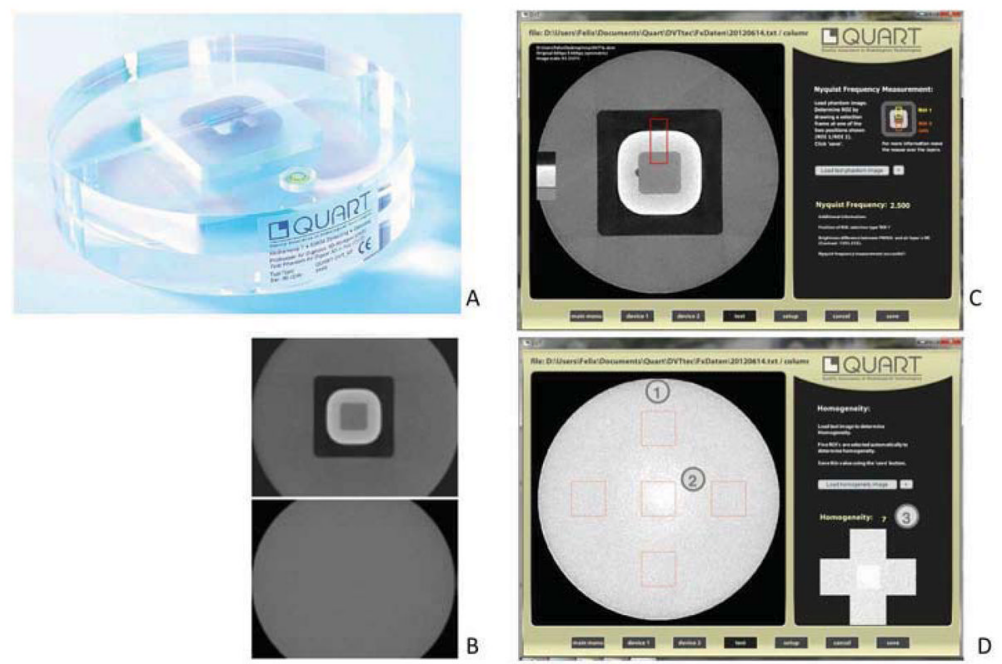

Figure 5.

Quart DVT_AP CBCT image quality system: A) phantom, B) Sample axial images of aluminum and air elements (top) and plexiglass layer (bottom), C) analysis software window for calculation of Nyquist frequency, D) analysis software window for calculating Homogeneity 


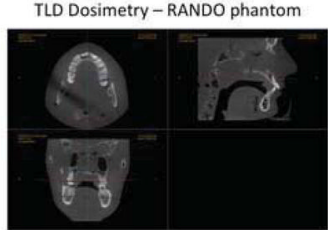

$13 \times 16 \mathrm{~cm}$ Standard scan Effective dose $=89 \mu \mathrm{Sv}$

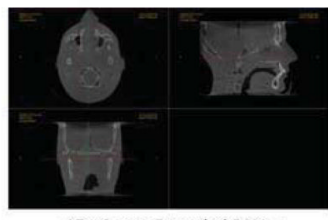

$17 \times 21 \mathrm{~cm}$ Extended Fov Effective dose $=74 \mu \mathrm{SV}$
OSL Dosimetry -RANDO phantom

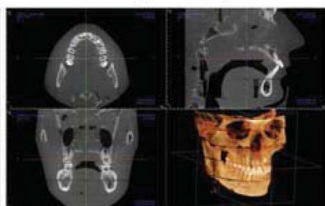

$13 \times 16 \mathrm{~cm}$ Standard scan $13 \times 16 \mathrm{~cm}$ Standard scan -
Effective dose $=85.5 \mu \mathrm{SV}$

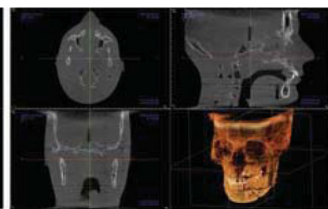

$17 \times 21 \mathrm{~cm}$ Extended FOV Effective dose $=67 \mu \mathrm{Sv}$
OSL Dosimetry-ATOM phantom

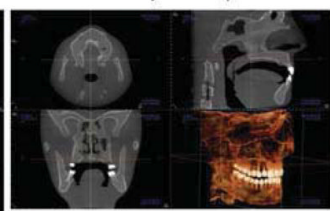

$13 \times 16 \mathrm{~cm}$ Standard scan

Effective dose $=85 \mu \mathrm{Sv}$

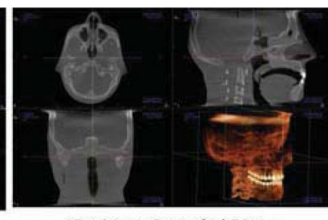

$17 \times 21 \mathrm{~cm}$ Extended FOV Effective dose $=69 \mu \mathrm{Sv}$

Figure 6.

Comparison of adult RANDO and ATOM phantoms, TLD and OSL dosimeter, Standard cephalometric and Extended FOVs 


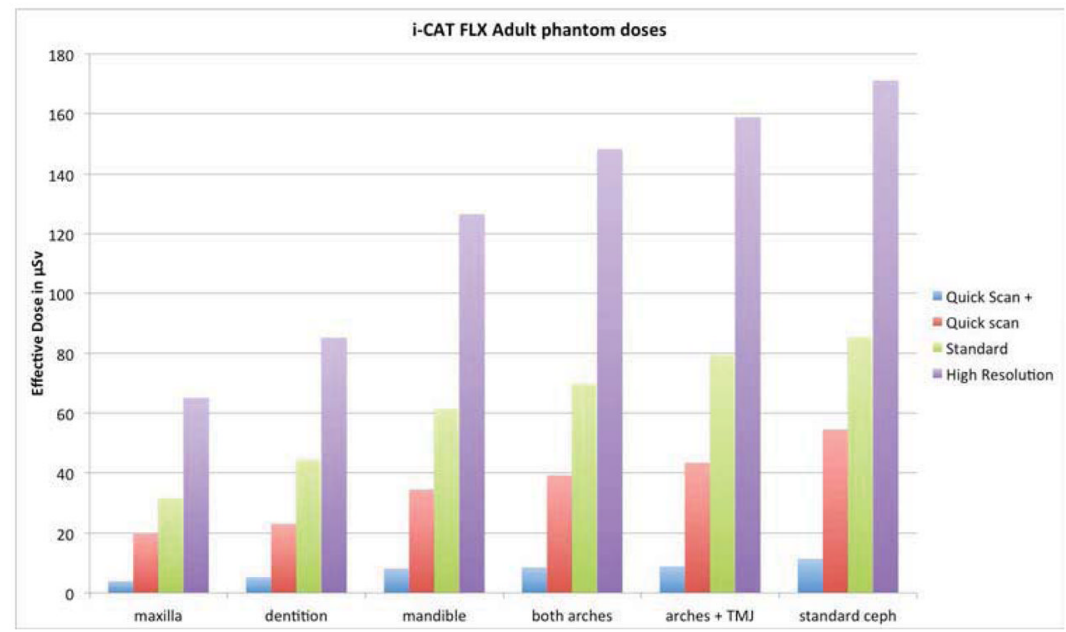

Figure 7.

Adult phantom effective dose by scan type and FOV 


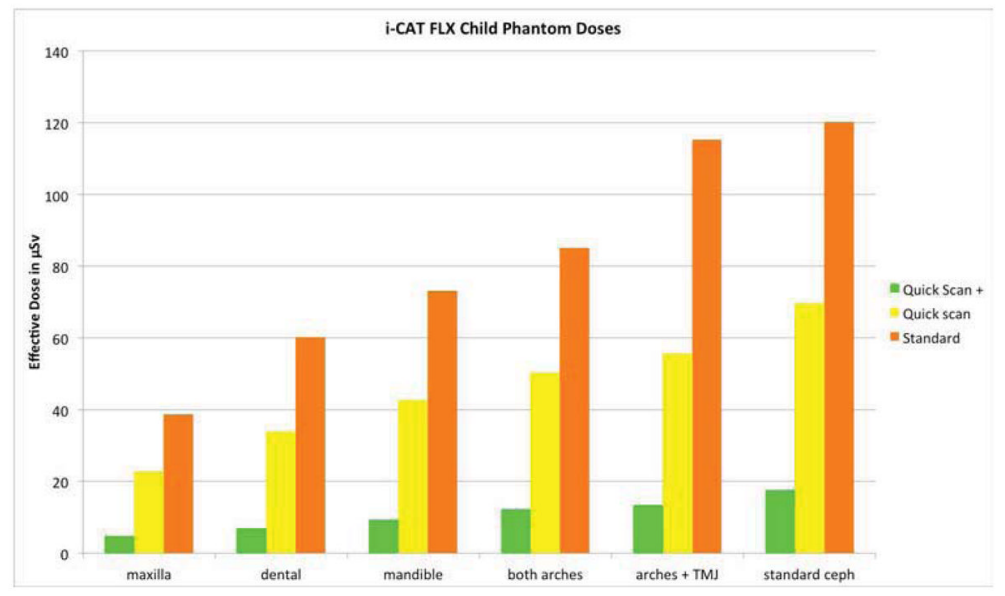

Figure 8.

Alternate depiction of Child phantom effective dose by exposure protocol and FOV 


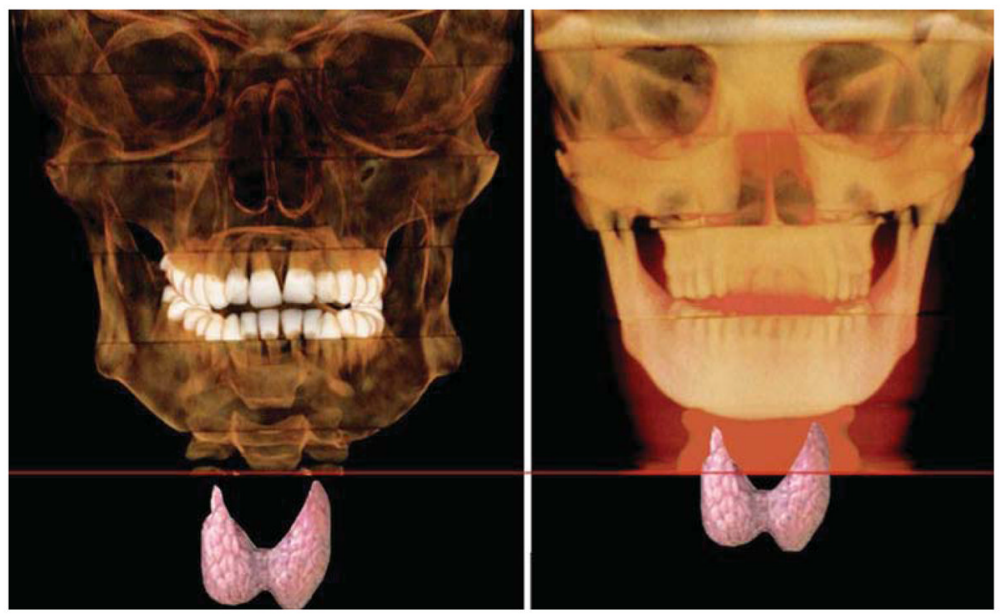

Figure 9.

Comparison of thyroid level in child and adult. Red line denotes lower edge of volume. 


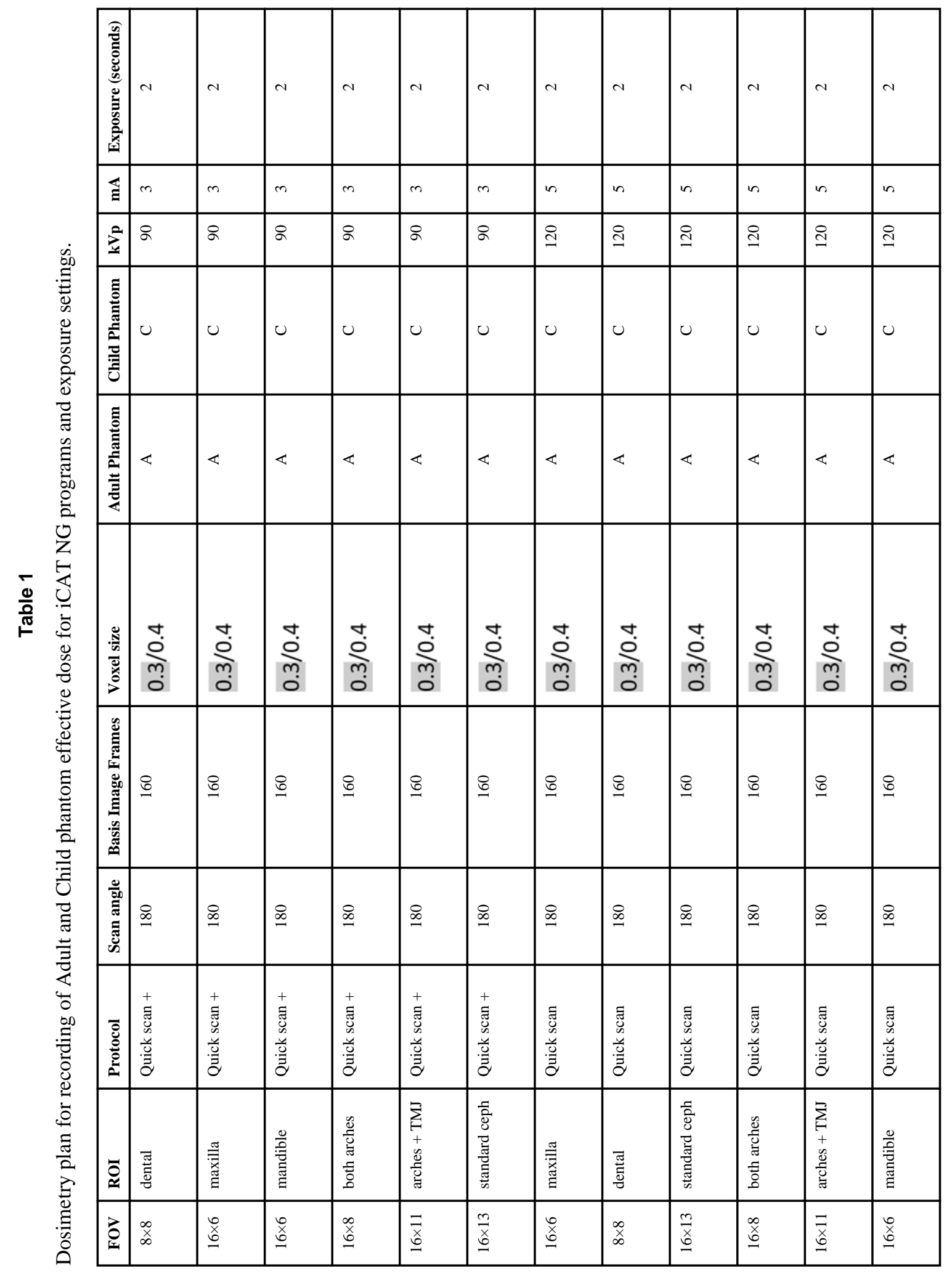




\begin{tabular}{|c|c|c|c|c|c|c|c|c|c|c|c|c|c|c|}
\hline 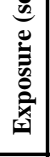 & $\hat{m}$ & $\dot{m}$ & $\dot{r}$ & $\dot{r}$ & $\dot{m}$ & $\overrightarrow{\dot{m}}$ & $\underset{\sim}{\stackrel{+}{r}}$ & $\stackrel{+}{\sim}$ & $\underset{\sim}{\stackrel{+}{r}}$ & $\stackrel{+}{\sim}$ & $\stackrel{+}{\stackrel{2}{*}}$ & $\stackrel{+}{\stackrel{r}{r}}$ & $\dot{m}$ & $\stackrel{+}{\stackrel{\sim}{r}}$ \\
\hline$\overleftrightarrow{\Xi}$ & in & in & in & in & in & in & in & in & in & in & in & in & in & in \\
\hline$\sum_{i}^{2}$ & తి & తి & $\stackrel{\text { తి }}{ }$ & తి & 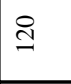 & తి & $\stackrel{\text { }}{ }$ & తి & తి & 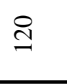 & తి & తి & తి & తి \\
\hline 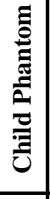 & 0 & $u$ & 0 & 0 & 0 & $u$ & & & & & & & & \\
\hline 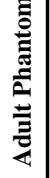 & $\varangle$ & $\varangle$ & $\varangle$ & $\ll$ & $\varangle$ & $\varangle$ & $\varangle$ & $\varangle$ & $\varangle$ & $\varangle$ & $\varangle$ & $\varangle$ & $\varangle$ & $\varangle$ \\
\hline 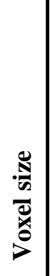 & $\frac{+}{\stackrel{0}{0}}$ & 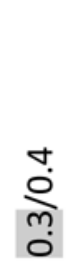 & $\frac{\dot{0}}{0}$ & 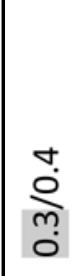 & 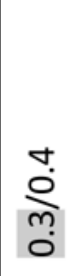 & 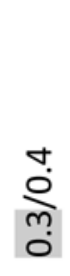 & 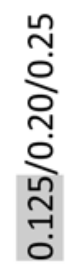 & 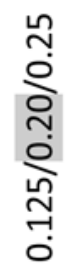 & 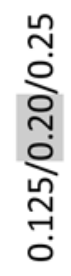 & 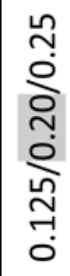 & 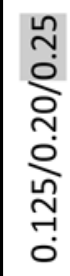 & 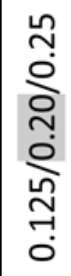 & $\frac{\dot{\sigma}}{\stackrel{m}{0}}$ & $\stackrel{+}{\stackrel{\oplus}{0}}$ \\
\hline 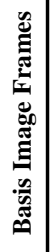 & \&্ল & \&্ল & $\underset{ల}{\stackrel{一}{ }}$ & \&్ల & \&্ল & \&্ల & \&్ర & \&్ర & 8 & \&్ర & 8 & \& & ষ্ল & 8 \\
\hline 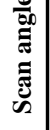 & 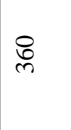 & 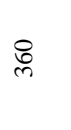 & : & : & 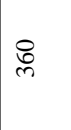 & 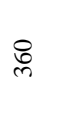 & 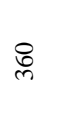 & $\underset{ల}{\stackrel{8}{ }}$ & : & : & : & : & ర్ల & : \\
\hline $\begin{array}{l}\bar{\Xi} \\
\stackrel{0}{0} \\
0 \\
0\end{array}$ & 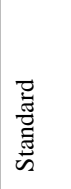 & 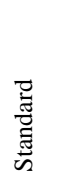 & 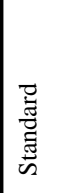 & 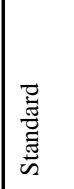 & 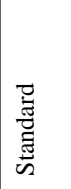 & 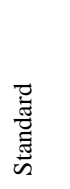 & 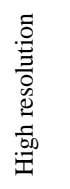 & 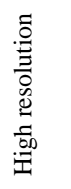 & 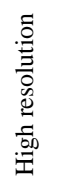 & 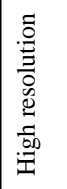 & 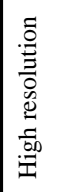 & 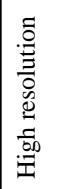 & 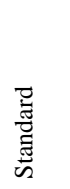 & 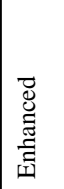 \\
\hline$\stackrel{0}{\approx}$ & 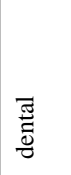 & 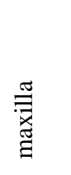 & 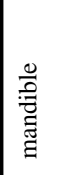 & 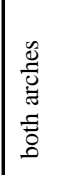 & 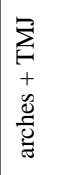 & 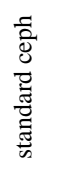 & 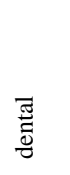 & $\begin{array}{l}\stackrel{\Xi}{\bar{Z}} \\
\stackrel{\Xi}{\Xi}\end{array}$ & 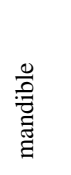 & 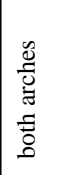 & 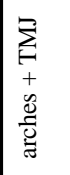 & 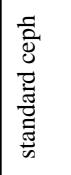 & $\begin{array}{l}\overrightarrow{3} \\
\text { 崮 }\end{array}$ & $\begin{array}{l}\text { bे } \\
\text { 呈 }\end{array}$ \\
\hline Dे & $\begin{array}{l}\infty \\
\infty \\
\infty\end{array}$ & $\stackrel{\stackrel{\leftrightarrow}{\circ}}{\circ}$ & $\begin{array}{l}\stackrel{0}{x} \\
\text { }\end{array}$ & \begin{tabular}{|l}
$\infty$ \\
\multirow{x}{*}{} \\
$\underline{\sigma}$
\end{tabular} & $\underset{\underline{x}}{\bar{x}}$ & $\underset{\underline{x}}{\stackrel{m}{x}}$ & $\begin{array}{l}\infty \\
\infty \\
\infty\end{array}$ & $\stackrel{\mathscr{x}}{\underline{x}}$ & 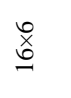 & 恖 & $\underset{\underline{x}}{\underline{x}}$ & 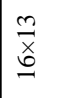 & 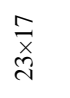 & $\begin{array}{l}\tilde{x} \\
\tilde{a}\end{array}$ \\
\hline
\end{tabular}




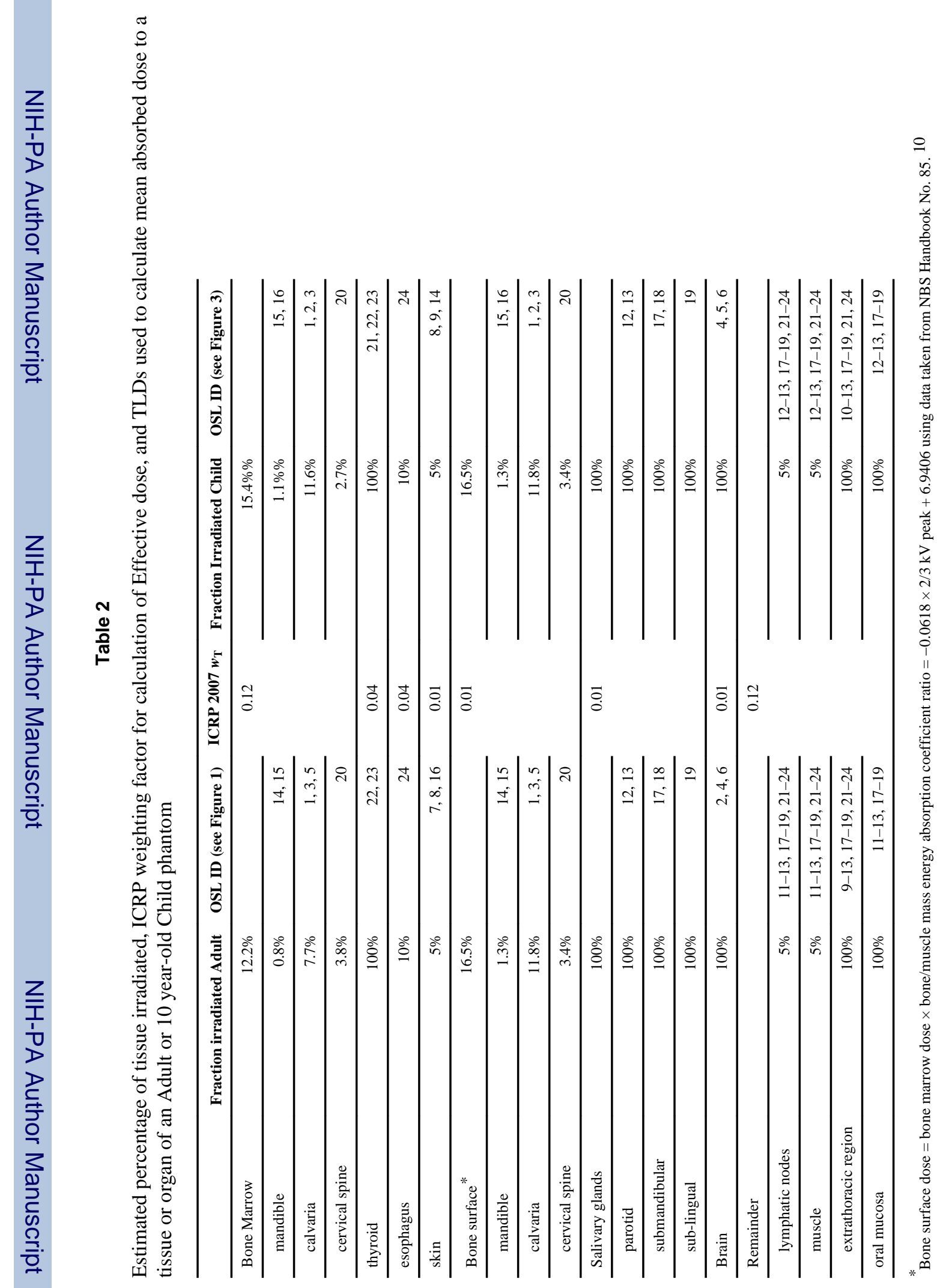




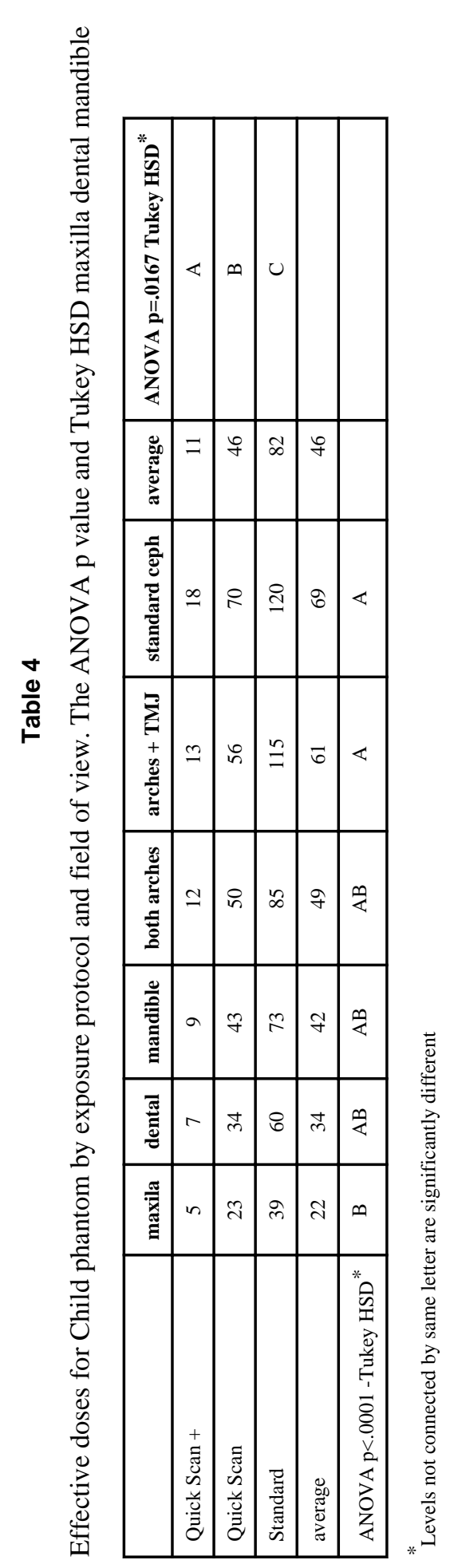

Am J Orthod Dentofacial Orthop. Author manuscript; available in PMC 2014 December 01. 


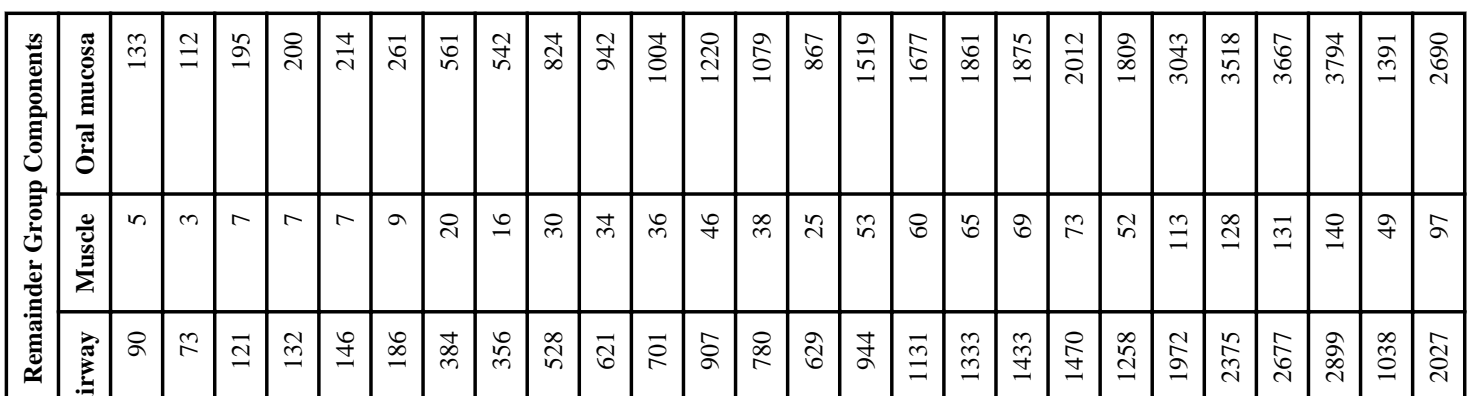

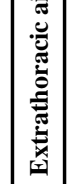

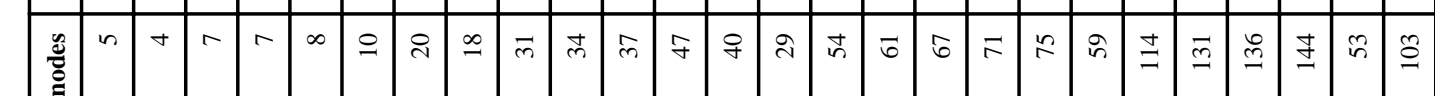

1

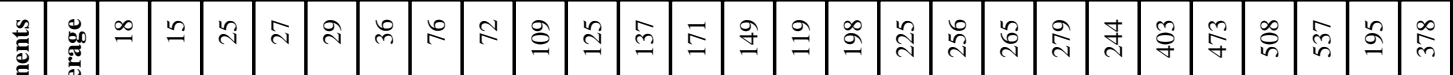

高竞

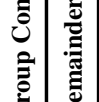

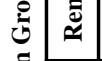

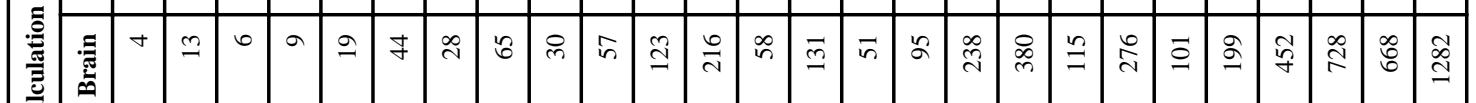

$\overline{8}$

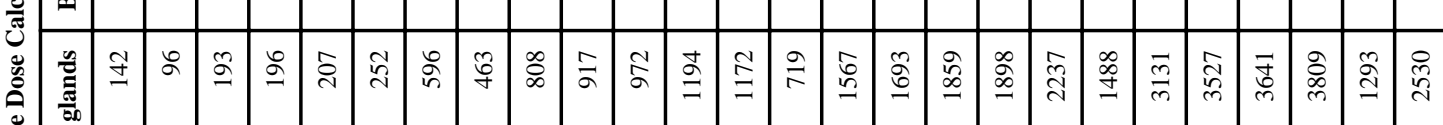

范

.

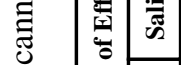

in

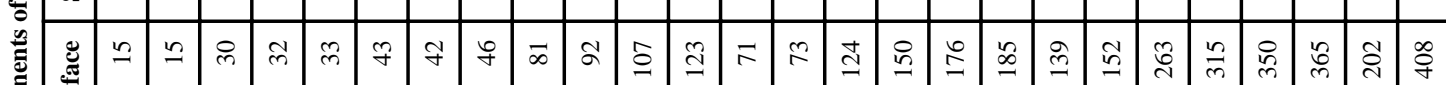

赔

8
8

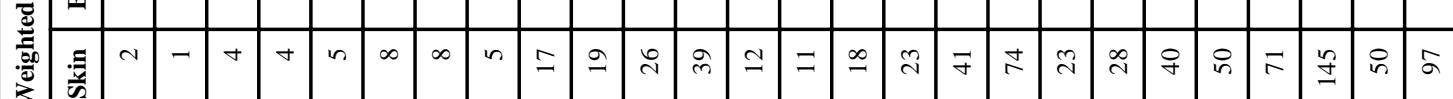

\begin{tabular}{|c|c|c|c|c|c|c|c|c|c|c|c|c|c|c|c|c|c|c|c|c|c|c|}
\hline & & & & & & & & & & & & & & & & & & & & 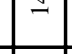 & & \\
\hline 9 & & -1 & $n$ & in & $\mid$ & 0 & $\therefore$ & $\infty$ & 9 & \begin{tabular}{l|l} 
व & (
\end{tabular} & | & $\begin{array}{l}\mathbf{a} \\
\text { : }\end{array}$ & \begin{tabular}{l|l}
$\infty$ \\
\end{tabular} & F & \begin{tabular}{|l|l}
7 & 9 \\
\end{tabular} & \begin{tabular}{l|l}
8 & 7
\end{tabular} & $\pi$ & \begin{tabular}{|l|l|} 
& $\bar{\alpha}$
\end{tabular} & \begin{tabular}{l|l}
$\vec{\infty}$ & $\infty$
\end{tabular} & \% & $\begin{array}{ll}\mathrm{m} & =\end{array}$ & \\
\hline & I & $\sigma$ & 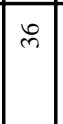 & \begin{tabular}{|l|} 
\\
\end{tabular} & \begin{tabular}{|l|} 
\\
$\infty$
\end{tabular} & \begin{tabular}{|l|}
\multirow{2}{*}{} \\
\end{tabular} & $\cong$ & $\infty$ & 守 & \begin{tabular}{l|l}
$E$ & $\Omega$
\end{tabular} & \begin{tabular}{|l|}
\multirow{2}{*}{} \\
\end{tabular} & $\bar{z}$ & 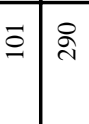 & क्ले & 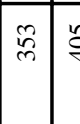 & \begin{tabular}{l|l}
\multirow{g}{*}{} & + \\
\end{tabular} & 索 & 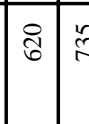 & \begin{tabular}{l|l}
$\stackrel{y}{n}$ & $q$ \\
\end{tabular} & $\vec{\infty}$ & 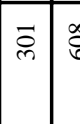 & \\
\hline & & \begin{tabular}{|l|} 
\\
\end{tabular} & $\sigma$ & $a$ & $\sigma$ & $\simeq$ & g & 9 & of & $\begin{array}{l}\text { f } \\
\text { in }\end{array}$ & 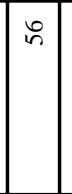 & $\bar{m}$ & \begin{tabular}{l|l} 
बi \\
\end{tabular} & $R$ & \begin{tabular}{|l|l|}
$\infty$ & $=$
\end{tabular} & \begin{tabular}{l|l}
$\infty$ & 8
\end{tabular} & 8 & 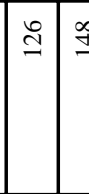 & 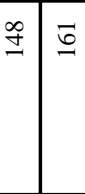 & \begin{tabular}{|l|l|} 
\\
\end{tabular} & \begin{tabular}{|l|l}
$\$$ & $\wp$
\end{tabular} & \\
\hline g. & & & $\vec{\infty}$ & \begin{tabular}{|l|} 
\\
$\infty$ \\
\end{tabular} & \begin{tabular}{|l|}
$\infty$ \\
$\infty$
\end{tabular} & $\stackrel{+}{=}$ & $\pi$ & $\stackrel{\square}{g}$ & 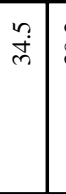 & 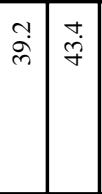 & \begin{tabular}{|l|l|} 
\\
\multirow{2}{*}{}
\end{tabular} & $\frac{7}{f}$ & \begin{tabular}{l|l}
$\stackrel{0}{m}$ & $\frac{3}{6}$
\end{tabular} & \begin{tabular}{ll}
$\infty$ \\
\multirow{B}{*}{}
\end{tabular} & \begin{tabular}{|l|l}
\multirow{2}{*}{} & 5 \\
\end{tabular} & $\begin{array}{ll}\infty \\
\infty\end{array}$ & $\ddot{\circ}$ & 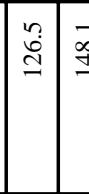 & 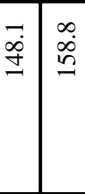 & $\vec{\Xi}$ & 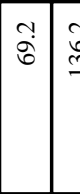 & \\
\hline & 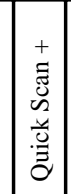 & 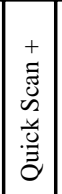 & 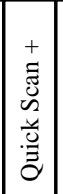 & 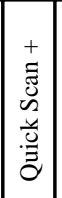 & 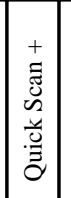 & 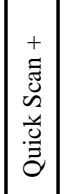 & 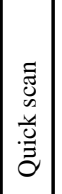 & | & 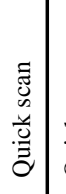 & 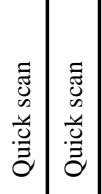 & 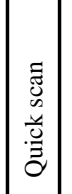 & & & 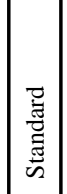 & 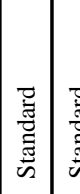 & 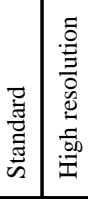 & 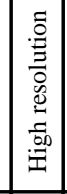 & 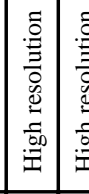 & 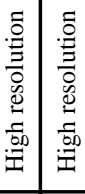 & 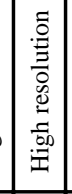 & 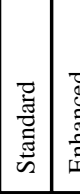 & \\
\hline & & 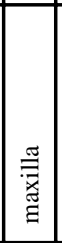 & 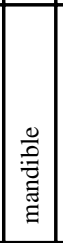 & 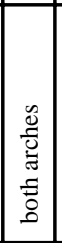 & 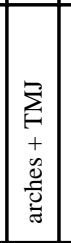 & 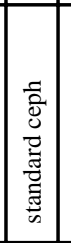 & 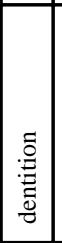 & 总 & 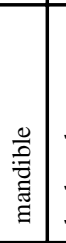 & 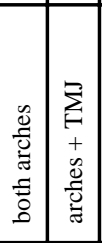 & 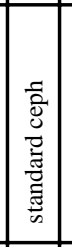 & 童 & 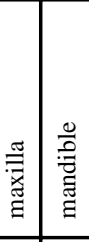 & 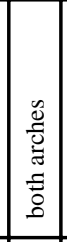 & 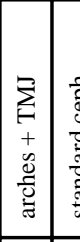 & 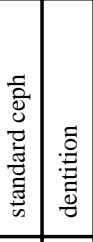 & 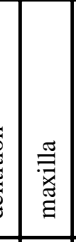 & 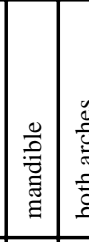 & 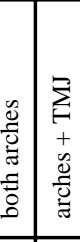 & 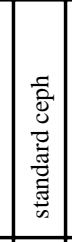 & 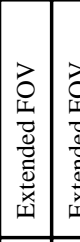 & 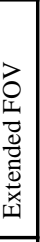 \\
\hline & $\mid \begin{array}{l}x \\
\infty\end{array}$ & 总 & $\underline{\hat{6}}$ & $\mid \begin{array}{l}\infty \\
\underline{\alpha} \\
-\end{array}$ & 斊 & $\mid \begin{array}{c}\stackrel{n}{\vec{x}} \\
\stackrel{\underline{x}}{-}\end{array}$ & $\mid$ & & 范 & 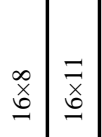 & 离 & $\begin{array}{ll}\infty & \\
\infty & \end{array}$ & 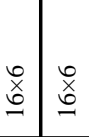 & 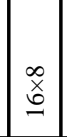 & 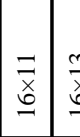 & 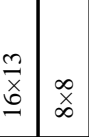 & 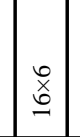 & 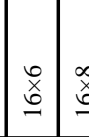 & 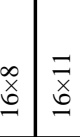 & $\underset{\underline{\underline{x}}}{\stackrel{\underline{x}}{-}}$ & 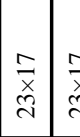 & 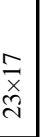 \\
\hline
\end{tabular}




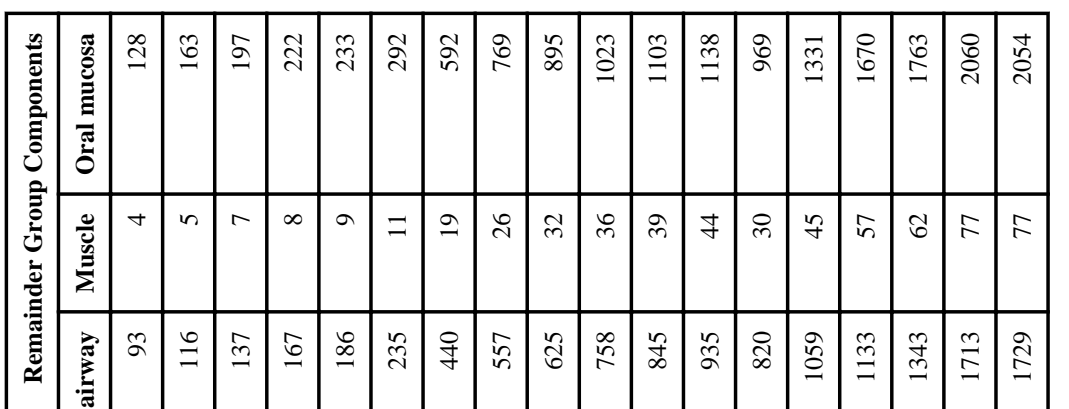

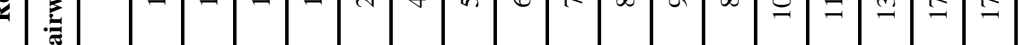

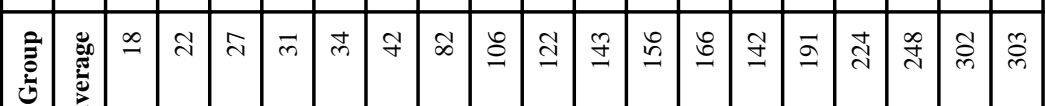

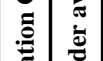

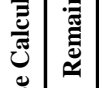

高

旅

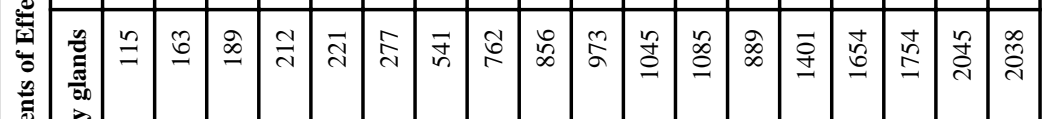

$\circ \stackrel{g}{\Xi}$ 产

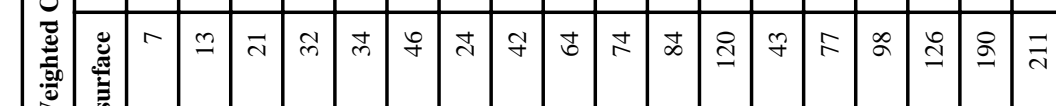

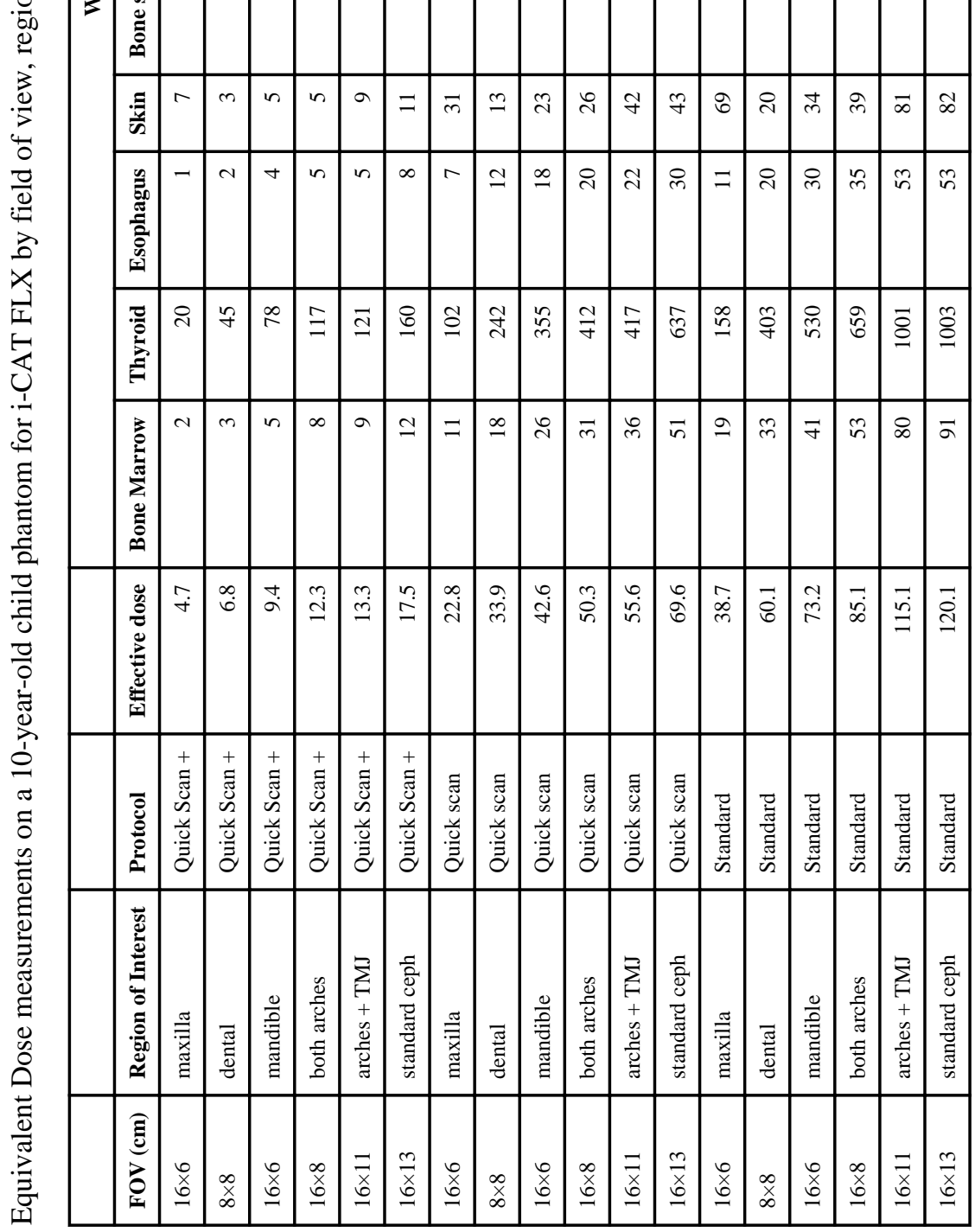




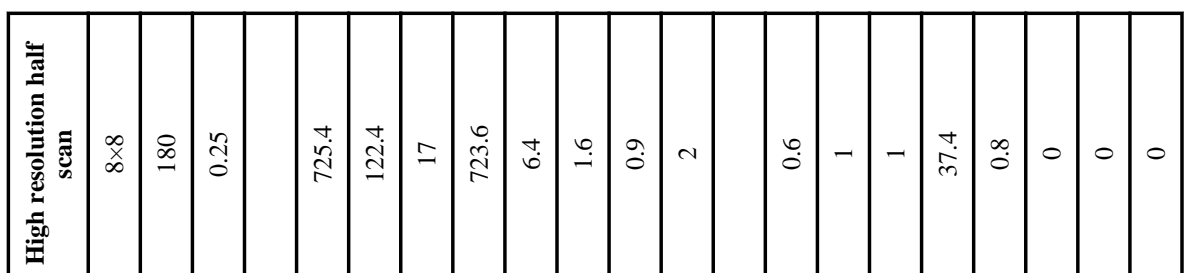

产

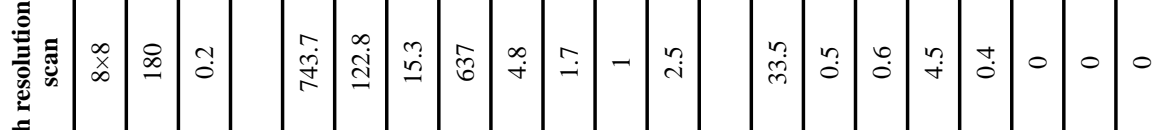

总

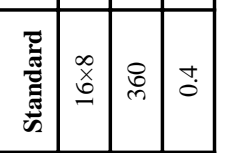

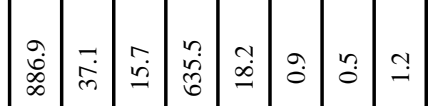

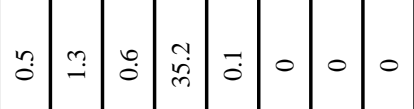

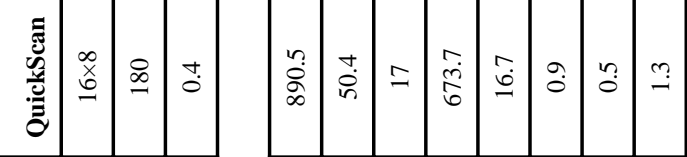

3 :

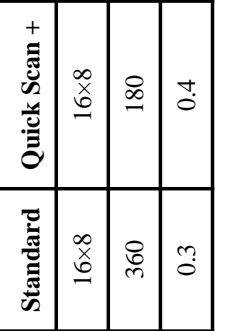

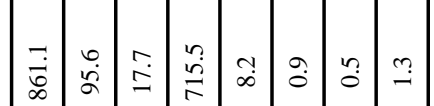

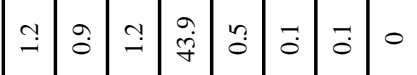

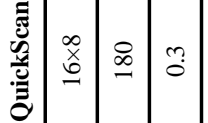

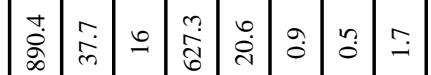

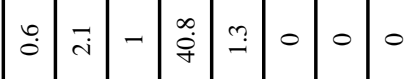

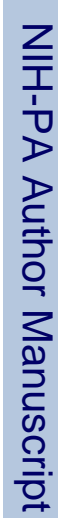

产
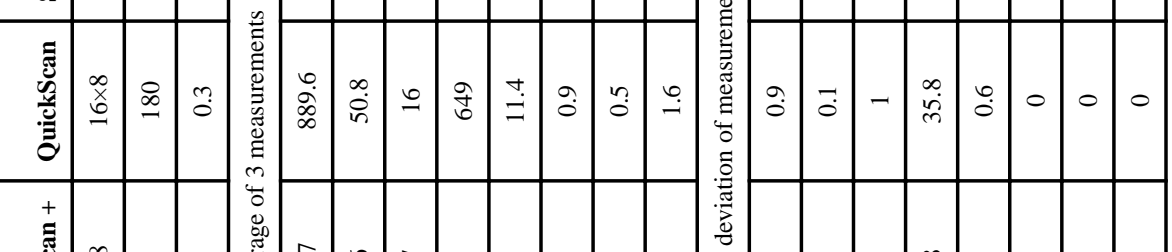

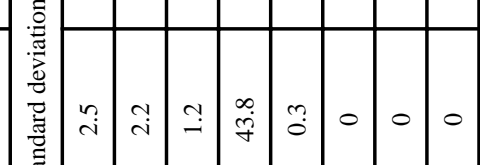

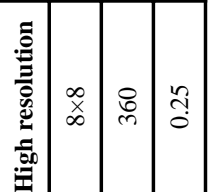

\begin{tabular}{|}
\hline \\
\hline
\end{tabular}

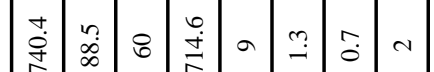

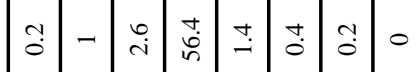

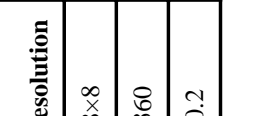

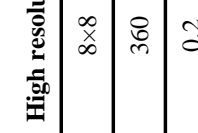

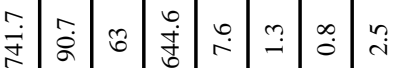

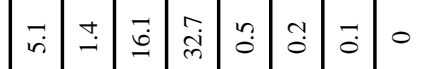

苛

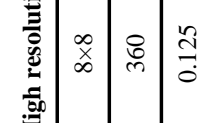

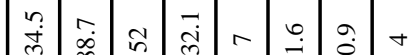

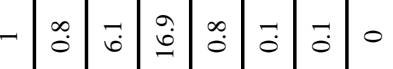

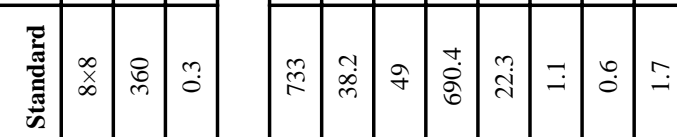

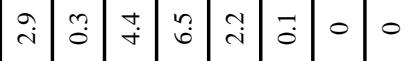

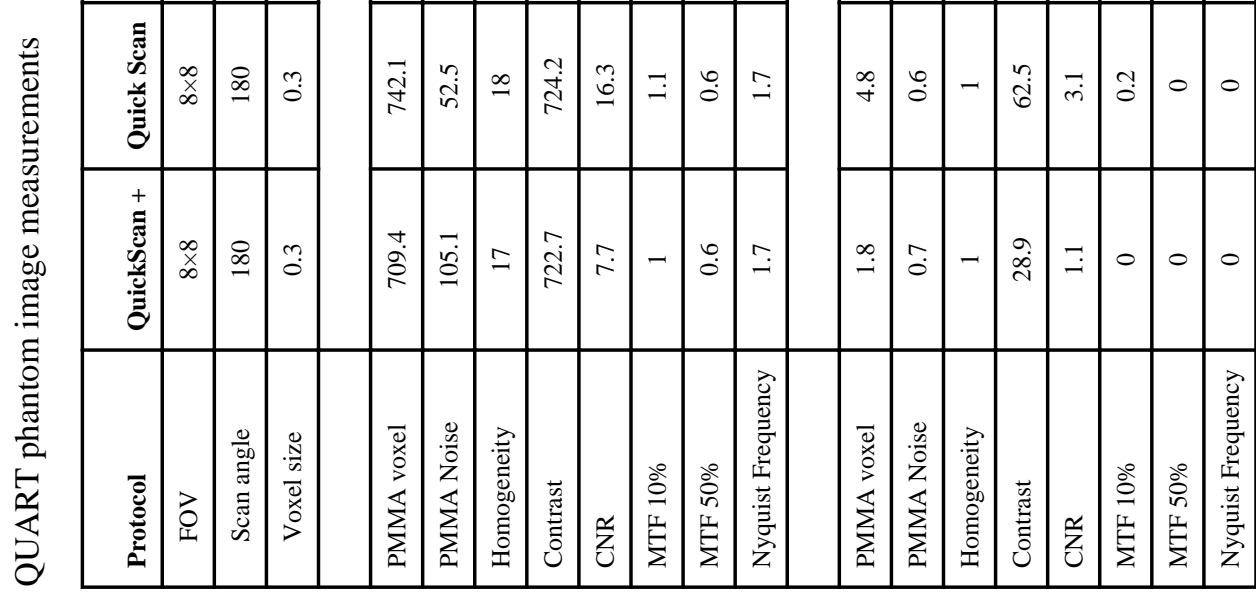

